\title{
Emerging Technologies in Hemostasis Diagnostics: A Report from the Australasian Society of Thrombosis and Haemostasis Emerging Technologies Group
}

\author{
Murray Adams, Ph.D., ${ }^{1}$ Chris Ward, M.B.Ch.B., Ph.D., ${ }^{2}$ Jim Thom, M.Sc., ${ }^{3}$ \\ Alessandra Bianchi, M.D., 4 Emma Perrin, M.Sc., 5 Douglas Coghlan, M.B.B.S., 6 \\ and Mark Smith, M.B.Ch.B. ${ }^{7}$
}

Technology in hemostasis laboratories has evolved enormously during the last 30 years. Although many scientists and clinicians will remember the traditional tilt-tube techniques to screen for coagulation abnormalities and to monitor anticoagulant therapy, the hemostasis laboratory today uses a variety of modern technologies. These include flow cytometry, chromogenic assays, molecular typing (e.g., polymerase chain reaction), immunologic assays (e.g., enzyme-linked immunosorbent assays), functional assays of specific coagulation proteins, and platelet function analyzers. Although these advances in technology have resulted in greater capability, productivity, sensitivity, specificity, and ultimately, improvement in the clinical care of patients, controversies and limitations remain. This article highlights new and emerging technologies in hemostasis and discusses whether they have improved or are likely to improve laboratory diagnostics by specifically addressing the following: (1) Can new technologies help predict likelihood of thrombosis recurrence? (2) Has an understanding of the role of a disintegrin-like and metalloprotease with thrombospondin type 1 motifs (ADAMTS13) in microangiopathy resulted in improved diagnostic methods for this disorder? (3) Does thrombelastography allow better definition of bleeding risk than conventional hemostasis assays, especially in settings of acute hemostatic pathology?

KEYWORDS: Hemostasis, laboratory testing, thrombin generation, thrombophilia, bleeding

\footnotetext{
${ }^{1}$ School of Human Life Sciences, University of Tasmania, Tasmania, Australia, and School of Biomedical Sciences, Curtin University of Technology, Western Australia; ${ }^{2}$ Department of Haematology and Transfusion Medicine, Royal North Shore Hospital, New South Wales, and University of Sydney, New South Wales, Australia; ${ }^{3}$ Haematology Department, Royal Perth Hospital, Western Australia, Australia; ${ }^{4}$ Department of Haematology, Concord Hospital, New South Wales, Australia; ${ }^{5}$ Queensland Health Pathology Service, Princess Alexandra Hospital, Queensland, Australia; ${ }^{6}$ Department of Haematology and Genetic Medicine, Flinders University, South Australia, Australia; ${ }^{7}$ Haematology Department, Canterbury Health Laboratories, Christchurch, New Zealand.
}

Address for correspondence and reprint requests: Murray Adams, Ph.D., School of Human Life Sciences, University of Tasmania, Locked Bag 1320, Tasmania 7250, Australia. E-mail: Murray. Adams@utas.edu.au.

Standardization, Quality Assurance, and Emerging Diagnostic Technologies in Hemostasis; Guest Editor, Emmanuel J. Favaloro, Ph.D., M.A.I.M.S.

Semin Thromb Hemost 2007;33:226-234. Copyright (C) 2007 by Thieme Medical Publishers, Inc., 333 Seventh Avenue, New York, NY 10001, USA. Tel: +1(212) 584-4662.

DOI 10.1055/s-2007-971808. ISSN 0094-6176. 


\section{CAN NEW TECHNOLOGIES HELP PREDICT LIKELIHOOD OF THROMBOSIS RECURRENCE?}

Conventional thrombophilia testing has helped to explain thrombophilic mechanisms, but has been less helpful in defining ongoing thrombotic risk. Despite the effectiveness of current anticoagulation therapy, defining the optimal duration of therapy remains a problem for clinicians and patients alike. Given the bleeding risk of vitamin $\mathrm{K}$ antagonists (VKAs) such as warfarin, indefinite anticoagulation should be restricted to patients with a high risk of recurrent venous thromboembolism (VTE). Follow-up of a large patient cohort after a first symptomatic deep vein thrombosis (DVT) demonstrated that more than $20 \%$ will suffer a recurrent event within 5 years. ${ }^{1}$ However, our inability to define which patients are in the 20 to $30 \%$ at high risk exposes the whole cohort to risk of complications from continued therapy with VKA. Clinical parameters, such as an idiopathic thrombosis, past history of VTE, or even being a male, are markers of increased risk of recurrence, but none of these factors alone are indications for indefinite warfarin. There is a clear need for a laboratory assay of hypercoagulability that predicts recurrent thrombosis.

\section{Thrombophilia Screening}

The ability of conventional thrombophilic factors to predict recurrence remains controversial. Earlier studies reported higher rates of recurrent VTE in the presence of antiphospholipid antibodies ${ }^{2,3}$ and elevated levels of factor (F) VIII:coagulant activity (C)., However, the high prevalence of these abnormalities in the normal population and uncertainty about laboratory criteria for identifying abnormal results have hampered the clinical application of these tests. In reviewed retrospective case-control studies, ${ }^{6}$ heterozygous carriage of either the FV Leiden or prothrombin 20210A mutations was not a significant risk factor for recurrence, but compound heterozygotes had higher hazard ratios (HRs) of 2.4 to 4.8. Several recent prospective studies have addressed this question. One or more thrombophilic markers (deficiencies of antithrombin, protein $\mathrm{C}$ and $\mathrm{S}$, acquired protein $\mathrm{C}$ resistance, FV R506Q and PT20210A mutations, hyperhomocysteinemia, and antiphospholipid antibodies) were found in $30 \%$ of 195 patients with a first episode of idiopathic proximal DVT and treated for either 3 or 12 months. ${ }^{7}$ After 46 months follow-up, recurrence rates were higher in the thrombophilic cohort (35.1\%) than in those with normal test results $(21 \% ; p=0.046)$. However, the excess of recurrent events was only seen in patients who received 3 months of anticoagulation; recurrence rates were similar in both the thrombophilic and normal cohorts after
12 months of treatment. The risks of stopping warfarin in patients with familial thrombophilia was addressed in 180 patients with either factor V Leiden or deficiencies of antithrombin, protein $\mathrm{C}$, or protein $\mathrm{S}$ who did not receive long-term anticoagulation after a first event. ${ }^{8}$ Recurrent VTE occurred at a rate of 5\%/year (during a mean 5.6-year follow-up) in this cohort, compared with a rate of $1 \% /$ year in those remaining on anticoagulation. Although this study found a higher risk in males compared with females, the recurrence rates seen here may not be high enough to justify indefinite anticoagulation in all patients with a thrombophilic defect. Therefore, testing for individual thrombophilic factors, with the possible exception of antiphospholipid antibodies, is unlikely to determine the duration of anticoagulation.

\section{D-Dimer}

At present, the most promising assay for the prediction of recurrence is an old assay revisited. Plasma levels of Ddimer have not been demonstrated to be specific for DVT and pulmonary embolism, but are a sensitive marker of fibrin formation, and thus a potential indicator of the activity of the coagulation pathways. In a small prospective study of $\mathrm{D}$-dimer levels during warfarin therapy, elevated levels at diagnosis normalized within 6 weeks in 13 patients with nonidiopathic DVT, whereas five of nine patients with idiopathic DVT showed persisting elevation. ${ }^{9}$ Recent studies have suggested that elevated D-dimer levels, typically measured after the cessation of warfarin therapy, may be a marker for recurrent thrombosis ${ }^{10,11}$; however, a subsequent study ${ }^{12}$ reported that thrombophilic carriers with normal D-dimer levels had a very low risk of recurrence, suggesting that a negative result may be a more useful predictor. The D-dimer assay used in this study (VIDAS D-Dimer enzyme-linked immunosorbent assay [ELISA]; bioMèrieux; Marcy l'Etoile, France) had a sensitivity of $62 \%$ and specificity of $65.6 \%$ across all subjects, but a negative predictive value of $94 \% .{ }^{12}$ Given that only $16 \%$ of patients with elevated D-dimer suffered a recurrence, its positive predictive value appears limited.

The contribution of $\mathrm{D}$-dimers was also compared with residual venous obstruction (RVO) in a prospective cohort study of 400 patients with idiopathic proximal DVT. ${ }^{13}$ In this study, elevated Ddimer level was an independent risk factor for recurrence at 2 years (HR, 3.32; 95\% confidence interval, 1.78 to 6.75 ), whereas $\mathrm{RVO}$ at the time of warfarin cessation did not contribute significantly. Of the patients with high $\mathrm{D}$-dimer levels, $25.9 \%$ had recurrent thromboembolic events, compared with $5.7 \%$ and $10.4 \%$ for those with normal D-dimer levels and the absence of presence of RVO, respectively. Taken together, these studies provide good evidence that 
D-dimer levels, measured after cessation of warfarin, can identify a group at low risk of recurrence. This hypothesis is being tested in a management study (PROLONG), in which elevated D-dimer levels after cessation become an indication to recommence warfarin. From the viewpoint of both the clinician and patient, it would be preferable to identify a high-risk cohort without stopping warfarin; whether D-dimer assays can be used for this purpose remains to be proven.

\section{Thrombin Generation}

Thrombin plays a central role in coagulation, modulating both pro- and antithrombotic pathways. Our conventional clotting times are poor markers of thrombin activity, given that $95 \%$ of thrombin generation occurs after the generation of fibrin. Thrombin generation assays have evolved considerably since the 1950s, as reviewed recently. ${ }^{14}$ Crucial advances include the use of a slow-reacting, fluorogenic substrate, allowing one-stage measurement in the presence of fibrin, and calibration against a nonclotting control. Among several competing systems, the most widely studied have been the endogenous thrombin potential $(\mathrm{ETP})^{15}$ and a commercial system, calibrated automated thrombography (CT), which can also measure thrombin generation in platelet-rich plasma. ${ }^{16,17} \mathrm{Mul}-$ tiple groups are now using the $\mathrm{CT}$ or thrombogram to screen different patient groups, and it has been recognized that the CT analysis can be performed on fresh and frozen-thawed PRP, but results are dependent on tissue factor and phospholipid concentrations. ${ }^{18}$ Further modifications, such as collection into corn trypsin inhibitor, have been proposed to prevent in vitro thrombin generation via the contact factor pathway. ${ }^{18}$ Although the sensitivity of these assays to thrombophilic conditions has been studied in small groups of patients, ${ }^{15,19-21}$ the recent availability of a standardized assay should enable researchers to study larger patient groups, and define the temporal relationships between thrombin potential, thrombotic events, and subsequent therapy.

The large Austrian Study on Recurrent Venous Thromboembolism $^{22}$ recently has confirmed an association between thrombin generation and VTE recurrence. Plasma samples were collected from 914 patients at a median of 13 months after ceasing anticoagulation for a first spontaneous VTE. It is important to note that this study excluded those with deficiencies of antithrombin III, protein C, protein $\mathrm{S}$, lupus anticoagulants, cancer, or pregnancy. Peak thrombin was higher in women than in men, and in those with the prothrombin 20210G mutation, but not in carriers of FV Leiden. By tertiles of peak thrombin, the risk of recurrence increased, so that the highest tertile ( $>400 \mathrm{nM}$ ) had a $20 \%$ risk at 4 years compared with $6.5 \%$ for the remaining two thirds $(p<0.001)$. Mean peak thrombin levels were higher in those with recurrence $(420 \mathrm{nM})$ than in those without $(349 \mathrm{nM})$, but the assay levels were similar for spontaneous and precipitated recurrent events. The authors propose that the threshold of $400 \mathrm{nM}$ can be used to identify a group at low risk of recurrence, for whom long-term warfarin is not appropriate. This is consistent with the D-dimer studies, but the low-risk group here comprises a larger proportion. Comparative studies are needed, using the widely used thrombin generation methods (ETP/CT) to determine if these are also predictive. Finally, there is now the potential to study the contribution of platelets to thrombin generation in these patients.

\section{Other Novel Assays For Predicting Risk of Thrombosis}

Other global assays of coagulation are under development that could identify high- or low-risk cohorts among VTE patients. These have been reviewed recently, ${ }^{14}$ and include indirect measures of thrombin measurement, such as thromboelastography (also discussed later in this review) and studies of fibrin polymerization. The overall hemostatic potential (OHP) developed by $\mathrm{He}$ et $\mathrm{al}^{23}$ quantitates fibrin generation and lysis in vitro, in response to trace amounts of thrombin/tissue factor and tissue plasminogen activator. Hypercoagulable OHP patterns may persist long after a thrombotic event ${ }^{24}$ and also were observed in a subset of patients receiving therapeutic doses of warfarin. ${ }^{25} \mathrm{As}$ with the D-dimer assays, testing of patients for recurrence risk ideally would be done before stopping warfarin. Additional modifications of the OHP assay may increase its sensitivity for thrombophilic defects. ${ }^{19}$ The role procoagulant phospholipid plays in clotting can also be assessed by a simple and easily automated technique that measures the ability of plasma, platelet-rich plasma, or whole blood to enhance the activity of activated $\mathrm{FX}^{26}$ This may prove to be a useful and rapid screening test for hypercoagulable patients.

There is growing consensus that the so-called reductionist approach to VTE (testing for an everincreasing number of thrombophilic factors) is of limited utility in predicting recurrence risk. ${ }^{14}$ The reductionist approach is also associated with a greater chance of generating false-positive results. ${ }^{27}$ Instead, it is hoped that global coagulation assays, which integrate multiple inherited, acquired, and temporary influences, will be more useful. Thrombin-generation assays are reproducible enough for clinical studies, and one system at least has shown a similar low recurrence risk in patients with low/normal levels of peak thrombin. ${ }^{6}$ The sensitivity of many of these 
assays to known thrombotic risk factors is not well defined. Patients with natural anticoagulant deficiencies and antiphospholipid antibodies often have been excluded from studies on the premise that they require indefinite warfarin after a first event. However, as a recent review noted, ${ }^{14}$ to be clinically useful, global assays of coagulation must do more than just detect the inherited thrombophilias. Until we have a greater range of treatment options, a first priority is to identify low-risk patients and limit their exposure to anticoagulation.

\section{HAS AN UNDERSTANDING OF THE ROLE OF ADAMTS13 IN MICROANGIOPATHY IMPROVED DIAGNOSTIC METHODS FOR THIS DISORDER?}

Mortality from thrombotic thrombocytopenic purpura (TTP) has declined substantially since early intervention with plasma exchange has become routine therapy. In addition, the pathophysiology of many cases of acute and chronic relapsing TTP has been defined following the recognition of the cleaving protease ADAMTS13 (a disintegrin-like and metalloprotease with thrombospondin type 1 motifs). Mortality from TTP was common until the 1970s, when it was discovered experimentally that treatment by plasmapheresis combined with replacement fresh frozen plasma was often an effective means of overcoming the acute phase. ${ }^{28}$ Early diagnosis and rapid initiation of this treatment has resulted in a dramatic improvement in survival of greater than $80 \%,{ }^{29}$ highlighting the need for clear diagnostic criteria.

In 1996, two groups independently isolated a protease that cleaved von Willebrand factor (vWF) multimers. ${ }^{30,31}$ This protein was later shown to be absent in congenital TTP ${ }^{32}$ as well as autoantibodyinduced, acquired TTP. ${ }^{33}$ The enzyme, then known as von Willebrand factor cleavage protease, was subsequently sequenced and identified as a metalloprotease and designated ADAMTS13. ${ }^{34}$ The discovery that ADAMTS13 deficiency was the cause of most cases of TTP led to an understanding of the probable pathophysiology. It had been known for some time that very large multimers of $\mathrm{vWF}$ were present in the plasma of many patients with TTP, ${ }^{35}$ and a series of in vitro experiments, using both recombinant and human-derived ADAMTS13, demonstrated that vWF multimers are cleaved by this enzyme, probably under conditions of high shear stress. It is likely that deficiency of ADAMTS13 leads to accumulation of highly procoagulant ultra large multimers of $\mathrm{vWF}$ in vivo with resultant thrombus formation in the microvasculature. ${ }^{36,37}$ In cases of microangiopathic hemolytic anemia where TTP seems likely, the laboratory now has several options to help establish the diagnosis. These are the demonstration of very high multimers of $\mathrm{vWF}$, a reduction in the functional or antigenic levels of ADAMTS13, or the presence of antibodies to the enzyme.

\section{vWF Multimer Assays}

Multimeric patterns of vWF traditionally have been used to help categorize the clinical types of von Willebrand disorder. Multimers are separated by electrophoresis through a low-concentration agarose gel, followed by immunoblotting. The bands can be visualized by either radioactive ${ }^{38}$ or enzyme-linked antibody to $\mathrm{vWF}^{39}$ The assay is complex and time consuming and therefore usually is only performed in specialized centers, with results rarely available quickly enough to be of value in reaching a diagnosis of TTP.

\section{ADAMTS13 Functional Assays}

These were reviewed in detail by Veyradier and Girma in 2004. ${ }^{40}$ At that time the available techniques were technically demanding, and were based on electrophoresis, ${ }^{30,31,41-43}$ measurement of residual vWF antigen ${ }^{44,45}$ or measurement of residual vWF activity ${ }^{46-49}$ after incubation of $\mathrm{vWF}$ with test plasma. Since then, there have been several major improvements, including an automated activity assay ${ }^{49}$ that can be completed within a few hours, ${ }^{50}$ a technique using the Impact-R (DiaMed, Cresier, Switzerland) cone and plate analyzer to measure the effect of TTP plasma on the adherence of normal platelets to a polystyrene well under conditions of high shear stress, ${ }^{51}$ and a fluorescent resonance energy transfer assay for ADAMTS13 activity that can be completed within 2 hours. ${ }^{52}$

\section{ADAMTS13 Antigen Assays}

Following an initial abstract reporting an ELISA in $2004,{ }^{53}$ the last 12 months have seen a major breakthrough in laboratory testing for ADAMTS13 and its antibodies. A technique, published in January 2006, used a peptide containing the ADAMTS13 cleavage site linked to a horseradish peroxidase. The method is rapid, sensitive, and reproducible. ${ }^{54}$ Rieger et al $^{55}$ reported a sandwich ELISA using polyclonal rabbit anti-ADAMTS13 as the capture antibody and peroxidase-complexed rabbit antihuman immunoglobulin (Ig) $\mathrm{G}$ as the detection antibody. This method was sensitive to low levels of ADAMTS13. In cases of inherited TTP, the authors demonstrated that circulating ADAMTS13 antigen/antibody complexes could be detected by the antibodies, producing normal antigenic levels and rendering the assay of limited value in such cases. The latest reported technique used a monoclonal ADAMTS13 as the capture antibody with two biotinylated anti-ADAMTS13 antibodies for detection. ${ }^{56}$ 
With this method, all 11 patients with acquired TTP had low ADAMTS13 levels. There are now commercially available ELISA kits from American Diagnostica (Stamford, CT) and Technoclone (Vienna, Austria).

\section{ADAMTS13 Antibody Assays}

Treatment of acquired TTP differs from treatment of congenital TTP in that plasma exchange and immunosuppression are needed in the former, whereas episodes of the familial form often can be managed successfully by fresh frozen plasma infusion. Demonstration of a circulating antibody is therefore clinically useful. Most of the assays described here have been adapted for the detection of antibody in cases of acquired TTP. Prior to assay, a mixture of test and normal plasma is incubated and the residual ADAMTS13 in the normal plasma is estimated using electrophoresis, ${ }^{33}$ the collagen-binding technique, ${ }^{45}$ estimation of vWF:ristocetin cofactor activity by aggregometry, ${ }^{47,48}$ or vWF:antigen by immunoradiometric analysis. ${ }^{45}$ Park et $\mathrm{al}^{57}$ purified patient $\mathrm{IgG}$ by affinity chromatography on protein A Sepharose prior to incubation with normal plasma and assessment of residual activity using the technique of Furlan et al. ${ }^{33}$ ELISA techniques are also suitable for detection of antibody. In the first technique described, Scheiflinger et $\mathrm{al}^{58}$ detected nonneutralizing antibodies not detected by a more traditional electrophoretic method. The more recent techniques of $\mathrm{Wu}$ et $\mathrm{al}^{54}$ and Rieger ${ }^{55}$ are also suitable for antibody detection and antibody kits are now commercially available.

Methods for the quantitation of ADAMTS13 have improved enormously in simplicity and precision since the enzyme was first described 10 years ago. It is now within the scope of most medium to large diagnostic laboratories to run these tests. In cases of congenital or acquired TTP, low ADAMTS13 levels or the detection of circulating antibodies are powerful diagnostic indicators. However, problems remain. Not all cases of clinically diagnosed idiopathic TTP have low ADAMTS13 levels. ${ }^{59}$ Normal levels can also be found in acquired TTP by ELISA, when circulating immune complexes that cause the clinical syndrome block the activity of the protease but do not cause its removal from the circulation. ${ }^{55}$ In these cases simultaneous measurement of antibody levels is important. Whether severe ADAMTS13 deficiency is a specific marker for TTP remains controversial ${ }^{60,61}$; it had been suggested that ADAMTS13 may also be reduced in other clinical conditions. $^{62,63}$

Nonetheless, it is likely that these issues will be resolved rapidly. The disorder is rare and to date there has only been limited availability of ADAMTS13 assays. Indeed it is likely that the classification of thrombotic microangiopathies will be refined on the basis of studies during the next few years. ${ }^{34,59}$ The newer techniques should also facilitate population studies, allow genetic counseling, optimize therapy, and help identify those at risk of recurrence.

\section{DOES THROMBOELASTOGRAPHY ALLOW BETTER DEFINITION OF BLEEDING RISK IN ACUTE HEMOSTATIC SETTINGS THAN CONVENTIONAL TESTS?}

Conventional hemostasis assays define bleeding risk, but have limitations in settings of acute hemostatic pathology. Acute bleeding in patients is a complex medical emergency, often complicated by the multifactorial nature of the bleeding. More than in any other patient, the coexistence of associated pathologies, such as sepsis, liver and/or renal failure, cardiac insufficiency, and the effects of multiple drugs can affect the hemostatic balance. The coagulopathy can often be very complex and the hemostatic balance can change rapidly due to the effects of the consumption of clotting factors, hyperfibrinolysis, defects of fibrin polymerization, hypothermia, hyper- or hypokalemia, or hypocalcemia secondary to citrate effect with calcium and magnesium chelation. ${ }^{64,65}$

The capacity to differentiate between surgical or hemostatic causes of bleeding is essential. Transfusion therapy is often given based on certain thresholds (hemoglobin, hematocrit, platelet count) and algorithms based on number and type of products infused. Inappropriate blood replacement can cause severe coagulopathies by further diluting depleted clotting factors. Abnormalities of laboratory tests are not specific and can be found also in nonbleeding patients. In addition, turnaround time of traditional hemostasis tests (prothrombin time, activated partial thromboplastin time, fibrinogen, thrombin time, and platelet count) results in reduced usefulness of the test because most often the patient has moved to a different hemostatic balance from the time the sample was taken. This means that traditional clotting tests will give us information only about the past and never about the present. Therapeutic decisions must be made in real time or as close to real time as possible.

The type of information gained from these tests is also limited because none of the current tests gives insight into the fibrinolytic component of the hemostatic balance, the quality of the platelet function, the presence of fibrin polymerization disorders, the presence of substances interfering with fibrin formation, mild fibrinogen deficiencies, or FXIII activity. It is well known that these tests correlate poorly with a bleeding tendency or propensity. Furthermore, testing on plasma reveals little about the cellular interactions in the hemostatic system that we now understand are complex and drive the final event of clot formation. More specialized testing of hemostasis also has limitations, including platelet aggregometry (which is technically challenging and time 
consuming) and platelet function analyzers (which provide a measure of primary hemostasis exclusively).

Clearly there is a need for more predictive tests in the acutely bleeding patient. The ideal in vitro test needs to recognize in vivo interactions between the classic elements involved in hemostasis, including the endothelium, platelets, and clotting factors, as well as other less recognized elements, including other cells (e.g., monocytes, cancer cells), metabolic effects from pathological states (e.g., uremia and paraproteinemia), medications, and fibrinolytic potential. Thrombin burst is also important, hence the intense interest in a global test of thrombin generation. Several commercial tests have been developed or are being evaluated (see previous discussion on thrombin generation assays), including thromboelastography (TEG).

\section{Thromboelastography}

TEG is a global assay in which the interaction of coagulation factors, platelets, fibrinolytic factors, inhibitors, drugs, and several other factors is assessed via the continuous registration of the stability of the forming blood clot under low shear conditions that mimic the flow conditions of venous blood. It provides a kinetic analysis of the entire clot formation and stabilization as well as clot dissolution by the fibrinolytic system. Quite distinct from traditional clotting tests, it is capable of providing information on some of the critical aspects of the clot formation process. The different parameters measured are dependent on the rate of formation, strength, elasticity, and firmness of the forming clot. $^{66,67}$

The use of whole blood allows ex vivo investigation of the clotting process and its interactions with cellular components such as leukocytes and erythrocytes. Furthermore, TEG is influenced by the interaction of platelets with coagulation proteins, including initial contact with thrombin, platelet aggregation, cross-linking of fibrin, and clot stabilization. This technology also measures clot dissolution and hence generates quantitative and qualitative information on fibrinolytic activity. No other routine clotting test currently is capable of providing all of this information. ${ }^{68}$ TEG can be used as a point-of-care test, such as in the operating theater where continuous monitoring of the hemostatic balance combined with a transfusion algorithm can lead to more appropriate use of blood products, resulting in significant savings. ${ }^{69}$

Although TEG provides a global overview and selective information about the main pathways in hemostasis, there are limitations associated with this technology. Although it is sensitive to a deficiency or excess of coagulation factors, specific clotting factor deficiencies cannot be identified. In addition, TEG does not reflect coagulation associated with endothelial cells and is sensitive only to severe, rather than mild forms of fibrinolysis. Currently, it is not standardized between laboratories due to the diversity in equipment, software, and variations in methodology ${ }^{70}$ has a relatively long measurement time, and requires technical expertise.

TEG has been explored extensively in surgery ${ }^{71,72}$ and trauma. ${ }^{73-76}$ It has also demonstrated promising results as a valuable test to monitor responses to administration of activated FVII for the treatment of patients with hemophilia and inhibitors in the setting of lifethreatening acute bleeding. ${ }^{77-79}$ Several authors have investigated the use of TEG as part of an algorithm to guide blood product replacement during surgery. The bulk of the published evidence relates to studies performed during cardiopulmonary bypass surgery. Despite the limitation that in most cases the size of the patient population analyzed is small, the overall conclusion was that TEG was useful in significantly reducing (three- to eight-fold) the use of blood products, particularly platelets and fresh frozen plasma, in the postoperative period. The reduction in use of blood products was achieved despite no differences or changes in intraoperative blood loss between patients monitored with TEG and the patients managed with standard transfusion therapy and laboratory tests. ${ }^{80-82}$ Other possible applications of TEG include identification of patients at higher risk of bleeding during and after cardiac surgery, ${ }^{83,84}$ monitoring the potential of FXIII administration to increase clot firmness, ${ }^{85}$ and identification of hypercoagulability following acute bleeding and massive transfusions. The future utility of TEG in diagnostic and clinical settings will be dependent on method standardization and software developments to allow for improved raw data analysis, and application to larger prospective clinical studies.

\section{REFERENCES}

1. Prandoni P, Lensing AW, Cogo A, et al. The long-term clinical course of acute deep venous thrombosis. Ann Intern Med 1996;125:1-7

2. Schulman S, Svenungsson E, Granqvist S. Anticardiolipin antibodies predict early recurrence of thromboembolism and death among patients with venous thromboembolism following anticoagulant therapy. Duration of Anticoagulation Study Group. Am J Med 1998;104:332-338

3. Kearon C, Gent M, Hirsh J, et al. A comparison of three months of anticoagulation with extended anticoagulation for a first episode of idiopathic venous thromboembolism. N Engl J Med 1999;340:901-907

4. Kraaijenhagen RA, Haverkamp D, Koopman MM, et al. High plasma concentration of factor VIIIc is a major risk factor for venous thromboembolism. Thromb Haemost 2000; 83:5-9

5. Kyrle PA, Minar E, Hisrchl M, et al. High plasma levels of factor VIII and the risk of recurrent venous thromboembolism. N Engl J Med 2000;343:457-462 
6. Kyrle PA, Eichinger S. The risk of recurrent venous thromboembolism: the Austrian Study on Recurrent Venous Thromboembolism (review). Wien Klin Wochenschr 2003; 115:471-474

7. Santamaria MG, Agnelli G, Taliani MR, et al. Thrombophilic abnormalities and recurrence of venous thromboembolism in patients treated with standardized anticoagulant treatment. Thromb Res 2005;116:301-306

8. Vossen CY, Walker ID, Svensson P, et al. Recurrence rate after a first venous thrombosis in patients with familial thrombophilia. Arterioscler Thromb Vasc Biol 2005;25: 1992-1997

9. Kévorkian J-P, Halimi C, Segrestaa J-M, et al. Monitoring of patients with deep-vein thrombosis during and after anticoagulation with D-dimer. Lancet 1998;351:571572

10. Fattorini A, Crippa L, D'Angelo SV, et al. Risk of deep vein thrombosis recurrence: high negative predictive value of D-dimer performed during oral anticoagulation. Thromb Haemost 2002;88:162-163

11. Palareti G, Legnani C, Cosmi B, et al. Risk of venous thromboembolism recurrence: high negative predictive value of D-dimer performed after oral anticoagulation is stopped. Thromb Haemost 2002;87:7-12

12. Palareti G, Legnani C, Cosmi B, et al. Predictive value of D-dimer test for recurrent venous thromboembolism after anticoagulation withdrawal in subjects with a previous idiopathic event and in carriers of congenital thrombophilia. Circulation 2003;108:313-318

13. Cosmi B, Legnani C, Cini M, et al. D-dimer levels in combination with residual venous obstruction and the risk of recurrence after anticoagulation withdrawal for a first idiopathic deep vein thrombosis. Thromb Haemost 2005; 94:969-974

14. Baglin T. The measurement and application of thrombin generation. Br J Haematol 2005;130:653-661

15. Wielders S, Mukherjee M, Michiels J, et al. The routine determination of the endogenous thrombin potential, first results in different forms of hyper- and hypocoagulability. Thromb Haemost 1997;77:629-636

16. Hemker HC, Giesen P, Al Dieri R, et al. The calibrated automated thrombogram (CAT): a universal routine test for hyper- and hypocoagulability. Pathophysiol Haemost Thromb 2002;32:249-253

17. Hemker HC, Giesen PLA, Al Dieri R, et al. Calibrated automated thrombin generation measurement in clotting plasma. Pathophysiol Haemost Thromb 2003;33:4-15

18. Gerotziafas GT, Despasse F, Busson J, et al. Towards a standardization of thrombin generation assessment: the influence of tissue factor, platelets and phospholipids concentration on the normal values of ThrombogramThrombinoscope assay. Thromb J 2005;3:16

19. Andresen MS, Abilgaard U, Liestol S, et al. The ability of three global plasma assays to recognize thrombophilia. Thromb Res 2004;113:411-417

20. Regnault V, Hemker HC, Wahlo D, et al. Phenotyping the haemostatic system by thrombography-potential for the estimation of thrombotic risk. Thromb Res 2004;114:539545

21. Eichinger S, Weltermann A, Phillip K, et al. Prospective evaluation of haemostatic system activation and thrombin potential in healthy pregnant women with and without factor V Leiden. Thromb Haemost 1999;82:1232-1236
22. Hron G, Kollars M, Binder BR, et al. Identification of patients at low risk for recurrent venous thromboembolism by measuring thrombin generation. JAMA 2006;296:397402

23. He S, Antovic A, Blömback M. A simple and rapid laboratory method for determination of haemostasis potential in plasma-II. Modifications for use in routine laboratories and research work. Thromb Res 2001;103:355-361

24. Antovic A, Blombäck M, Bremme K, et al. Increased hemostasis potential persists in women with previous thromboembolism with or without APC resistance. J Thromb Haemost 2003;1:2531-2535

25. Morel-Kopp M-C, Curnow J, Aboud M, et al. Discrepancies between the overall coagulation potential (OCP) assay and international normalised ratio (INR) in warfarin-treated patients. J Thromb Haemost 2005;3(suppl 1):1376

26. Exner T, Joseph J, Low J, et al. A new activated factor Xbased clotting method with improved specificity for procoagulant phospholipids. Blood Coagul Fibrinolysis 2003;14: 773-779

27. Favaloro EJ, Soltani S, McDonald J, et al. Laboratory identification of familial thrombophilia: do the pitfalls exceed the benefits? A reassessment of $\mathrm{ABO}$-blood group, gender, age, and other laboratory parameters on the potential influence on a diagnosis of protein $\mathrm{c}$, protein $\mathrm{s}$, and antithrombin deficiency and the potential high risk of a false positive diagnosis. Lab Hematol 2005;11:174184

28. Byrnes JJ, Khurana M. Treatment of thrombotic thrombocytopenic purpura with plasma. N Engl J Med 1977;297: 1386-1389

29. George JN. How I treat patients with thrombotic thrombocytopenic purpura-hemolytic uremic syndrome. Blood 2000; 96:1223-1229

30. Furlan M, Robles R, Lämmle B. Partial purification and characterization of a protease from human plasma cleaving von Willebrand factor to fragments produced by in vivo proteolysis. Blood 1996;87:4223-4234

31. Tsai HM. Physiological cleavage of von Willebrand factor by a plasma protease is dependent on its conformation and requires calcium ion. Blood 1996;87:4235-4244

32. Furlan M, Robles R, Solenthaler M, et al. Deficient activity of von Willebrand factor cleavage-cleaving protease in a patient with thrombotic thrombocytopenic purpura. Blood 1997;89:3097-3103

33. Furlan M, Robles R, Solenthaler $M$, et al. Acquired deficiency of von Willebrand factor cleavage-cleaving protease in a patient with thrombotic thrombocytopenic purpura. Blood 1998;91:2839-2846

34. Zheng X, Chung D, Tkayama TK, et al. Structure of von Willebrand factor-cleaving protease (ADAMTS13), a metalloprotease involved in thrombotic thrombocytopenic purpura. J Biol Chem 2001;276:41059-41063

35. Moake JL, Rudy CK, Troll JH, et al. Unusually large plasma FVIII:von Willebrand factor multimers in chronic relapsing thrombotic thrombocytopenic purpura. N Engl J Med 1982 307:1432-1435

36. Lämmle B, Kremer Hovinga JA, Alberio L. Thrombotic thrombocytopenic purpura. J Thromb Haemost 2005;3: 1663-1675

37. Moake JL. Von Willebrand factor, ADAMTS-13 and thrombotic thrombocytopenic purpura. Semin Hematol 2004;41:4-14 
38. Meyer D, Obert B, Pietu G, et al. Multimeric structure of factor VIII/von Willebrand factor in von Willebrand's disease. J Lab Clin Med 1980;95:590-602

39. Baillod P, Affolter B, Kurt GH, et al. Multimeric analysis of von Willebrand factor by vertical sodium dodecyl sulphate agarose gel electrophoresis, vacuum blotting technology and sensitive visualisation by alkaline phosphatase complex. Thromb Res 1992;66:745-755

40. Veyradier A, Girma J-P. Assays of ADAMTS-13 activity. Semin Hematol 2004;41:41-47

41. Allford SL, Harrison P, Lawrie AS, et al. von Willebrand factor-cleaving protease activity in congenital thrombotic thrombocytopenic purpura. Br J Haematol 2000;111:12151222

42. Van der Plas RM, Schiphorst ME, Huizinga EG, et al. von Willebrand factor proteolysis is deficient in classic, but not in bone marrow transplantation-associated, thrombotic thrombocytopenic purpura. Blood 1999;93:3798-3802

43. Krizek DM, Rick ME. A rapid method to visualize von Willebrand factor multimers by using agarose electrophoresis, immunolocalization and luminographic detection. Thromb Res 2000;97:457-462

44. Obert B, Tout H, Veyradier A, et al. Estimation of the von Willebrand factor-cleaving protease in plasma using monoclonal antibodies to vWF. Thromb Haemost 1999;82:13821385

45. Veyradier A, Obert B, Houllier A, et al. Specific von Willebrand factor-cleaving protease in thrombotic microangiopathies. Blood 2001;98:1765-1772

46. Gerritsen HE, Turecek PL, Schwartz HP, et al. Assay of von Willebrand factor (vWF)-cleaving protease based on decreased collagen binding affinity of degraded vWF: a tool for the diagnosis of thrombotic thrombocytopenic purpura (TTP). Thromb Haemost 1999;82:1386-1389

47. Aronson DL, Krizek DM, Rick ME. A rapid assay for the vWF protease. Thromb Haemost 2001;85:184-185

48. Schneppenheim R, Budde U, Oyen F, et al. von Willebrand cleaving protease and ADAMTS-13 mutations in childhood TTP. Blood 2003;101:1845-1850

49. Böhm M, Vigh T, Scharrer I. Evaluation and clinical application of a new method for measuring activity of von Willebrand factor-cleaving metalloprotease (ADAMTS-13). Ann Hematol 2002;81:430-435

50. Kostousov V, Fehr J, Bombeli T. Novel, semi-automated, 60min-assay to determine von Willebrand factor cleaving activity of ADAMTS-13. Thromb Res 2006;118:723-731

51. Shenkman B, Budde U, Angerhaus D, et al. D. ADAMTS13 regulates platelet adhesion under flow. Thromb Haemost 2006;96:160-166

52. Kokame K, Nobe Y, Kokubo Y, et al. FRETS-VWF73, a first fluorogenic substrate for ADAMTS-13 assay. $\mathrm{Br} \mathrm{J}$ Haematol 2005;129:93-100

53. Yagi $H$, Matsumoto $M$, Iwamoto $T$, et al. Heightened proteolysis of plasma ADAMTS-13 antigen in patients with thrombotic thrombocytopenic purpura. Blood 2004;104: 3946(Abst)

54. Wu J-J, Fujikawa K, Lian EC, et al. A rapid enzyme linked assay for ADAMTS-13. J Thromb Haemost 2006;4:129-136

55. Rieger M, Ferrari S, Kremer Hovinga JA, et al. Relation between ADAMTS-13 activity and ADAMTS-13 antigen levels in healthy donors and patients with thrombotic microangiopathies (TMA). Thromb Haemost 2006;95:212220
56. Feys HB, Liu F, Dong N, et al. ADAMTS-13 plasma level determination uncovers antigen absence in acquired thrombotic thrombocytopenic purpura and ethnic differences. J Thromb Haemost 2006;4:955-962

57. Park YD, Yoshioka A, Kawa K, et al. Impaired activity of von Willebrand factor-cleaving protease may predict the occurrence of hepatic veno-occlusive disease after stem cell transplantation. Bone Marrow Transplant 2002;29:789-794

58. Scheiflinger F, Knöbl P, Trattner B, et al. Nonneutralizing IgM and IgG antibodies to von Willebrand factor cleaving protease in a patient with thrombotic thrombocytopenic purpura. Blood 2003;102:3241-3243

59. Kremer Hovinga JA, Studt JD, Alberio L, et al. von Willebrand factor-cleaving protease (ADAMTS13) activity determination in the diagnosis of thrombotic microangiopathies: the Swiss experience. Semin Hematol 2004;41:7582

60. Remuzzi G. Is ADAMTS-13 deficiency specific for thrombotic thrombocytopenic purpura? J Thromb Haemost 2003; 1:632-634

61. Tsai HM. Is severe deficiency of ADAMTS-13 specific for thrombotic thrombocytopenic purpura? Yes. J Thromb Haemost 2003;1:625-631

62. Loof AH, van Vliet HH, Kappers-Klunne MC. Low activity of von Willebrand factor-cleaving protease is not restricted to patients suffering from thrombotic thrombocytopenic purpura. Br J Haematol 2001;112:1087-1088

63. Moore JC, Hayward CP, Warkentin TE, et al. Decreased von Willebrand factor protease activity associated with thrombocytopenic disorders. Blood 2001;98:1842-1846

64. Koh MB, Hunt BJ. The management of peri-operative bleeding. Blood Rev 2003;17:179-185

65. Levy JH. Massive transfusion coagulopathy. Semin Hematol 2006;43(1, suppl 1):S59-S63

66. Rivard GE, Brummel-Ziedins KE, Mann KG, et al. Evaluation of the profile of thrombin generation during the process of whole blood clotting as assessed by thromboelastography. J Thromb Haemost 2005;3:2039-2043

67. Kolde HJ, Strobel GA. Whole blood global haemostasis assay via collagen mediated activation of the haemostasis system. Ann Hematol 2003;82(suppl 1):S147

68. Mallett SV, Cox DJA. Thromboelastography. Br J Anaesth 1992;69:307-313

69. Avidan MS, Alcock EL, Da Fonseca J, et al. Comparison of structured use of routine laboratory tests or near patient assessment with clinical judgment in the management of bleeding after cardiac surgery. Br J Anaesth 2004;92:178-186

70. Luddington RJ. Thrombelastography/thromboelastometry. Clin Lab Haematol 2005;27:81-90

71. Piraccini E, Zanzani C, Caporossi E. Intraoperative coagulation monitoring and small bowel transplantation: a way to explore. Transplant Proc 2006;38:823-825

72. Gillies BS. Thromboelastography and liver transplantation. Semin Thromb Hemost 1995;21(suppl 4):45-49

73. Kaufmann CR, Dwyer KM, Crews JD, et al. Usefulness of thromboelastography in assessment of trauma patient coagulation. J Trauma 1997;42:716-720

74. Vorweg M, Hipp RFJ, Schindler A, et al. Management of coagulation in trauma patients using a new monitoring method. Anesth Analg 1996;82:S54

75. Fries D, Innerhofer P, Schobersberger W. Coagulation management in trauma patients. Curr Opin Anaesthesiol 2002;15:217-223 
76. Savry C, Quinio P, Lefevre F, et al. Manageability and potential for haemostasis monitoring by near-patient modified thromboelastometer (Rotem) in intensive care unit. Ann Fr Anesth Reanim 2005;24:607-616

77. Pusateri AE, Park MS. Mechanist implications for the use and monitoring of recombinant activated factor VII in trauma. Crit Care 2005;9(Suppl 5):S15-S24

78. Ingerslev J, Christiansen K, Calatzis A, et al. Management and monitoring of recombinant factor VII. Blood Coagul Fibrinolysis 2000;11(suppl 1):S25-S30

79. Kawaguchi C, Takahashi Y, Hanesaka Y, et al. The in vitro analysis of the coagulation mechanism of activated factor VII using thromboelastogram. Thromb Haemost 2002;88:768-772

80. Shore-Lesserson L, Manspeizer H, DePerio M, et al. Thromboelastography-guided transfusion algorithm reduces transfusion in complex cardiac surgery. Anesth Analg 1999; 88:312-319

81. Royston D, von Kier S. Reduced haemostatic factor transfusion using heparinase-modified thromboelastography during cardio-pulmonary by-pass. Br J Anaesth 2001;86: 575-578

82. Anderson L, Quasim I, Steven M, et al. An audit of red cell and blood product use after institution of thromboelastography in a cardiac intensive care unit. Br J Haematol 2003; 121(suppl 1):80

83. Williams GD, Bratton SL, Riley EC, et al. Coagulation tests during cardiopulmonary bypass correlate with blood loss in children undergoing cardiac surgery. J Cardiothorac Vasc Anesth 1999;13:398-404

84. Cammerer U, Dietrich W, Rampf T, et al. The predictive value of modified computerized thromboelastography and platelet function analysis for postoperative blood loss in routine cardiac surgery. Anesth Analg 2003;96:5157

85. Wettstein P, Haeberli A, Stutz M, et al. Decreased factor XIII availability for thrombin and early loss of clot firmness in patients with unexplained intraoperative bleeding. Anesth Analg 2004;99:1564-1569 